\title{
Research and Application on the Public-Private-Partnership under the Supply-Side Reform
}

\author{
Li Penglin'1, Guo Yitong', 2, ,
}

\author{
${ }^{1}$ Department of Management, Xi'an University of Science and Technology, The Forest of Steles, \\ Xi'an, Shanxi, China \\ ${ }^{2}$ Department of Management, Xi'an University of Science and Technology, The Forest of Steles, \\ Xi'an, Shanxi, China \\ b540839375@qq.com
}

Keywords: Supply-side reform, the PPP mode, Infrastructure construction, Investment method.

\begin{abstract}
Under the China's new normal, applying and popularizing the Public-PrivatePartnership is of crucial importance for latest economics. This paper, based on the accordance of the Supply-side Reform and the Public-Private-Partnership (PPP model), will illustrate the meaning and the classification of the PPP model, along with the analysis of its application and the process of operation under Chinese environment. I will summarize the problems in the operation; and accordingly offer a relevant solution, for the sake of the PPP model's sustainable development in China.
\end{abstract}

\section{Introduction}

Different from the demand-oriented economical policy, The Supply-side Reform is based on the production and the supply of products with more and better input to optimize crucial aspects, for instance, labor forces, land, capital and innovation etc. This reform makes the overall system to accommodate the change of demand structure more flexible; its long-term goal is in the adjustment and optimization of economic structure, along with the guaranteed promotion in the quality of economic growth.

In the 2017 19th CPC National Congress, there's one emphasis in the intensification of the Supply-Side Reform: we need to construct the economic system, which can bring a better role for the market and the government to perform sufficiently.The Public-Private-Partnership actually has the direct coherence with this Supply-Side Reform; since as the aspect, concerning the public service and the infrastructure construction, Public-Private-Partnership can further promote the new investment and financing mode of the market. Facing the huge demand of the infrastructural construction, the traditional investment with the direct domination of local government could not afford to last longer. In contrast, the PPP model has brought in some new opportunities for the local government to ease the financial pressure; also gaining a new round of promotion and application at this stage. The application of the PPP model is not only the tool for elevating the efficiency of the project construction, but also, more importantly, the useful means for the government to transform the function and perform the suitable efficiency in applying the marketing resources. Overall, this mode has a fundamental effect on aspects like economic growth, the development of the society and the accordance of the location and sustainability of the resource environment and etc.

\section{The basic introduction of PPP model}

\subsection{The meaning of the PPP model}

It is cooperation between private and public sectors, also indicating the cooperation between the government and the social capitals, in order to provide certain public services or products. Also this is constructed jointly as one partner-contractual relationship including forms like franchising. 
Under the PPP model, the private business and the government, within this financing project, through cooperation can achieve the share of risks, benefit and the final common goal[1].Since the 90s 20th century, the PPP model began its adventure in our country; and we could summarize the development into five stages: exploration, experimental unit, promotion, adjustment and the regulation. However, after enduring over 10 years' high-speed economic growth and 4 trillions stimulus plan, there are crucial problems like overwhelmed debt over local government, the postponed economic growth and the lag-behind industrial structure. Therefore, the PPP model is seen as one means to ease the governmental debt, transform the function of government, reform the financial system and finally promote the market-oriented reform. According, the new round of reform for PPP model has then begun. [2]

\subsection{The introduction for primary forms}

Recently, the PPP model has been applied worldwide. However, due to the difference in the cognition and the individual development of PPP model in each country, there are also differences shown on the classification of the PPP model. In China, scholars, responsible in researching this model, mainly utilize the financing model, the share of revenue and risk and the belongings of property right as reference factors for the classification; and then, it could be classified into three categories: outsourcing projects, franchising projects and privatized projects $^{[3]}$.(PPP model's classification and its features to be seen in Table1)

Table 1.PPP model's classification and its features

\begin{tabular}{|c|c|c|c|}
\hline & Outsourcing projects & Franchising projects & Privatized projects \\
\hline $\begin{array}{l}\text { Source of } \\
\text { investment }\end{array}$ & fully financed by the government & $\begin{array}{l}\text { The private department is } \\
\text { responsible for partial } \\
\text { projects or } \\
\text { investment }\end{array}$ & $\begin{array}{l}\text { financed by the } \\
\text { private department }\end{array}$ \\
\hline $\begin{array}{l}\text { Profit and } \\
\text { risk sharing } \\
\text { percentage }\end{array}$ & $\begin{array}{l}\text { the government is buying services from } \\
\text { the private department, and based on the } \\
\text { quality and quantity of the department to } \\
\text { pay for the relevant fees. The } \\
\text { government takes the full responsibility } \\
\text { over the risk of project investment and } \\
\text { operation }\end{array}$ & $\begin{array}{l}\text { the government and private } \\
\text { department will divide the } \\
\text { profit and risk percentage } \\
\text { by the agreement }\end{array}$ & $\begin{array}{l}\text { the private department } \\
\text { will have the full } \\
\text { profit after the } \\
\text { established project and } \\
\text { will also endure the } \\
\text { full risk. }\end{array}$ \\
\hline Ownership & by the government & $\begin{array}{l}\text { the capital of the project } \\
\text { wil be transferred to the } \\
\text { government after the } \\
\text { franchising period }\end{array}$ & $\begin{array}{l}\text { the private department } \\
\text { will have the full } \\
\text { project ownership }\end{array}$ \\
\hline $\begin{array}{l}\text { Primary } \\
\text { forms }\end{array}$ & BOOT (build-own-operate-turn over) & $\begin{array}{l}\text { BOT (build-operate-turn } \\
\text { over), TOT (transfer- } \\
\text { operate-turn over) ROT } \\
\text { (reform-operate-transfer) }\end{array}$ & $\begin{array}{l}\text { the private department } \\
\text { will have the full } \\
\text { project ownership }\end{array}$ \\
\hline $\begin{array}{l}\text { Suitable } \\
\text { scope }\end{array}$ & unprofitable project & $\begin{array}{l}\text { operating project and } \\
\text { project prepared to operate }\end{array}$ & $\begin{array}{l}\text { project prepared to } \\
\text { operate }\end{array}$ \\
\hline
\end{tabular}

\section{The application of PPP model in industries of China}

\subsection{The industrial distribution and its latest stage of PPP model project}

Until the end of 2017, China's platform project library about the PPP integrated information has shown that the documented project has accumulated to 14059, with total the investment of 17.74 trillion; within these amounts, there are 7137 projects in the phase of preparing, purchasing, operating and handing over. Also, there are 31 states, autonomous region and the Xinjiang Corps involved and 19 relevant industries. Until the end of December 2017, the top 3 
documented industries into the platform library, in order, are municipal engineering, transportation, and ecological and environmental protection. This, in total, constructed 59\% of the platform library. Then the top 3 industries, which acquire the most investment, in order, are municipal engineering, transportation, and comprehensive development of urbanization, which has constructed $71.6 \%$ in the library. ${ }^{4]}$ (The distribution data of PPP documented project in December, 2017, seen in Fig1)

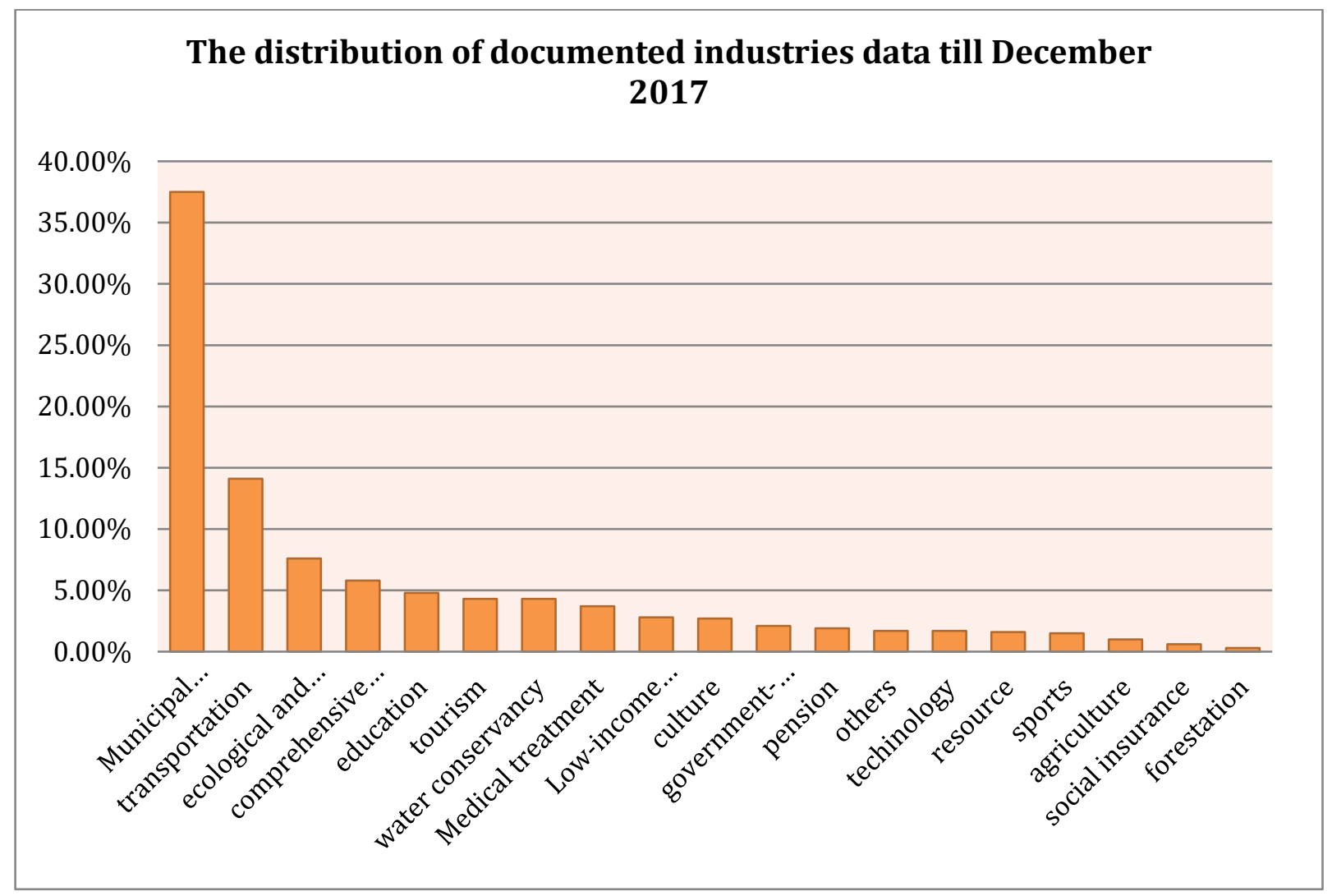

Fig1.The distribution data of PPP documented project in December

Right now, there's around $50.67 \%$ of documented projects are still in recognition phase, and only $19.38 \%$ projects are in the operation phase. (The distribution of the in-phase of documented project. can be seen in Table 2)

Table 2.The distribution of the in phase of documented project

\begin{tabular}{|l|l|l|l|l|}
\hline & $\begin{array}{l}\text { recognition } \\
\text { phase }\end{array}$ & prepation phase & purchasing phase & operation phase \\
\hline $\begin{array}{l}\text { Project size(billion } \\
\text { yuan) }\end{array}$ & $73,036.83$ & $26,119.12$ & $31,521.46$ & $45,760.51$ \\
\hline Project number & 7,123 & 2,025 & 2,186 & 2,725 \\
\hline
\end{tabular}

\subsection{The analysis of China's application of PPP model}

\subsection{1 the current situation illustration in applying PPP model.}

Concerning the operation of PPP model, around $83.4 \%$ projects are mainly based on the BOT model; however, there are still other models like BTO, ROT, EPC, etc still being utilized. When to consider the PPP project in china, on one side, the ones relevant to construction are easily adjusted; however, on the other side, the mode to apply PPP project is still too unitary. Therefore, to recognize and prepare for the PPP projects, those responsible departments need to incorporate more actual situations and the special needs of the individual with a better choice of more 
flexible and suitable operation method.

The operation method normally is: in the method of investing, authorizing or purchasing the service, the government will cooperate with some social companies to form one project stock company. Then as this company, to call for tenders of suitable projects. The project stock company will sign one special operation contract with the government, saying the company will have the full responsibility for the projects' construction, operation and financing in one designated period. However, when the period expires, the company will exit and transfer the project to the government. [5] (til 2017, the operation mode of documented PPP projects seen in Table 3.)

Table 3.the operation mode of documented PPP projects

\begin{tabular}{|c|c|c|c|c|c|c|c|c|c|}
\hline & BOT & Others & BOO & TOT & ROT & $\begin{array}{l}\text { TOT+BO } \\
\mathrm{T}\end{array}$ & O\&M & $\mathrm{MC}$ & $\begin{array}{l}\text { TOT }+ \\
\text { BOO }\end{array}$ \\
\hline $\begin{array}{l}\text { Project } \\
\text { size } \\
\text { (billion } \\
\text { ) }\end{array}$ & $\begin{array}{l}13,463 . \\
8\end{array}$ & $\begin{array}{l}22,627 . \\
4\end{array}$ & $\begin{array}{l}8,334.4 \\
8\end{array}$ & $\begin{array}{l}5,377.5 \\
0\end{array}$ & $\begin{array}{l}2,106.8 \\
0\end{array}$ & $3,362.03$ & $\begin{array}{l}863.7 \\
0\end{array}$ & $\begin{array}{l}34.1 \\
7\end{array}$ & 92.88 \\
\hline $\begin{array}{l}\text { Project } \\
\text { number }\end{array}$ & 10,432 & 1,293 & 888 & 674 & 337 & 275 & 144 & 12 & 4 \\
\hline
\end{tabular}

In the mode of PPP model operation, based on the project data, the most widely applied ones are the BOT and the BOO mode. BOT mode means to build, operate and transfer. The BOT has shown a great adaptive capacity in China due to the fact that the PPP projects here are mainly related to cities' infrastructure construction. How does BOT mainly works: the government and the social business company will form a project stock company together, then authorizing it the right to design, finance, and construct within the designed period for construction. During the period of franchising after, the company will also be given the right to operate, maintain and serve. Once the franchising period ends, the capital and the right in this project will all be transferred to the government. Another mode BOO means to build, own and operate. It is evolved from the BOT, but with more focus on the privatization of the project ownership. In the contact, the government and the social business will have to emphasize the public welfare of the project, without even mentioning transferring the final project to the government. (BOT mode operation, seen in Fig2)

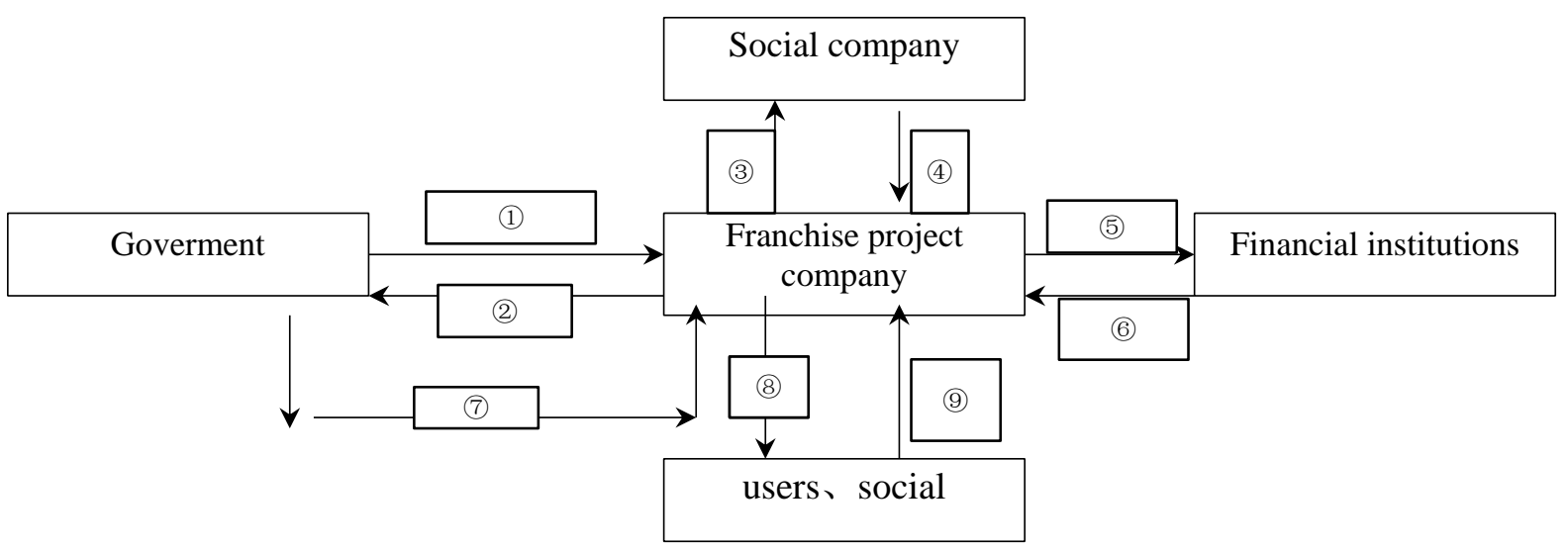

(1) Franchise rights, (2) regulatory, (3) return, (4) invest, (5) Principal and interest, (6) Credit borrowing, (7) subsidy, (8)operating, (9) Service charge.

Fig2.BOT Project operation

3.2.2 The analysis over the operation process of $P P P$ projects in China 
(1) The recognition phase:

This is the phase to select the PPP projects. The government will first, based on the submitted projects by each department or collaborated social business, to form one special project team. Then, through the relevant submitted materials like (the basic introduction, the financial affordability, the comments on its value, the research on its feasibility, the supposed operation plan and the investment plan etc), the team will then filter out projects on the 4 aspects : optimizing operation, sharing the financial pressure, elevating social services and operation efficiency. Also, combining the former operation experience of similar projects, the team will finally pick one relevant project to report to the department with direct higher authority.

(2) The preparation phase:

After the department has approved to develop the project, there are two relevant departments formed under the government. The first department will be focused on accordance, mainly responsible for the supervision, problem and conflict solving etc. The second will be focused on the design and the planning of the project. Both departments will be responsible for drafting the operation plan to include the situation illustration, construction of multiparty risk allocation framework ant the detailed operation process. The method to transact, purchase and the design of contract, including specifying the supervising role of government in the project and the publicwelfare are all needed to be included in the detailed process. After all the requirements fulfilled, the higher authorized department will then evaluate and comment on this plan.

(3) The purchasing phase:

If the operation plan has been examined to pass, the governmental department will give invitation of tender to social business, and accordingly conduct the primary qualification examination for each interested business. After the business is examined to be qualified, the government will then draft relevant documents for purchasing process, including the content of invitation of tender, the notice, the method, the relevant aptitude of business, and the former operation situation, the official approval from the upper department, the time and place for the opening of the tender, the judges team, the criteria for judging and all the required legislation document. After the tender, the government will have a further discussion with the tenderwinning business. The content, concerning the discussion meeting and the final result will all be shown to the public. And after reporting it to the upper governmental department as well, the two can then sign the project contract.

(4) The operation phase:

The specific department, appointed by the government will form one project stock company (project company) with the social business. And the governmental department will shoulder the responsibility to supervise the total situation of each expense. The project company, during the designed period of franchising, need to plan, construct, finance, and operate and the final maintain the project. And for the government side, it will replace the project company to coordinate the relevant financing and supervise the overall financial status. Also, based on the contract, the government will have to conduct the mid-term evaluation of the project's operation performances. Accordingly, the department will design relevant solution on the exposed problem and meanwhile report to the government for declaration. During the designing and the constructing process, the project company needs to set up a complete governing department, the clear board of directors, and specified responsibility for senior executive along with the designing construction plan. On the contrary, the government department needs to have the accordance responsibility, and perform the supervision of capital throughout the operation process. And also construct the midterm evaluation of the operation. After the project is well constructed, the project company will have the franchise right, including the service fee paid by the government or other social business. But, based on the contract, the project company will also give the bonus to certain departments and business. Before the contract expires, the government needs to hire the professional agency to evaluate the progression and the capital in the preparation for the handover. 
(5) The hand over phase:

The government will need to decide the way for hand over based on the contract ( 2 situations could happen: one is the hand over after the contract expires, one is before the expiration). After conducting a complete examination and evaluation to make sure the capital and the right is in perfect condition, the government can then perform the handover process with the social business.

After the handover, the dominant government department, along with other departments, will have a full-side evaluation result and notify the public as well.

\section{The problems behind China's PPP mode.}

As one creative method for infrastructure operation and investment method, the PPP mode is still in its popularizing stage. Through its progression, there are still problems of aspects illustrated below:

\subsection{The recognition deviation of PPP model}

Even though PPP model has become one crucial factor to the supply-side reform, the local government and social business, still, has certain deviation onto its recognition. For the local government, it lacks the right concept to develop PPP model; rather, it only focuses on its financing function, without concerning its actual advantage in optimizing the project governing and the social governance. Also, in the long term, the local government has always occupied the leading role in economic growth and construction. Actually, public-welfare and the commerce have a certain contradiction, resulting the function of the market being suppressed. Meanwhile, a lot of department and social business does not have the recognition of equity and contract. When it comes to the factors like leadership transfer in the local department, and the lack of sufficient communication between departments, the final public infrastructure project hasn't reached a good agreement with the social business, resulting a poor participation of the two responsible parties.

\subsection{The lack of legislation system, and the system design aspect need to be furnished}

PPP model in China is mainly focused on the infrastructure construction with characters like long period, huge investment and complicated process. Therefore, PPP model needs to have a detailed and systematic instruction from its primary recognition phase to its final hand over phase. However, based on the current system in our country, the application of PPP model still has several incompatibilities as several supports to apply the model only give help from the surface without even touching the inner core operation details and regulations. Meanwhile, the legislation system about the PPP model hasn't formed systematically, as the majority document is about political suggestion. Therefore the insufficiency on the legislation aspect has brought huge risk to the investment parties, resulting a less optimistic participation for the social business, as the actual turn out for the investment couldn't reach the expectation.

\subsection{The project's yield is too low and there's incompatibility between the profit and the risk.}

One crucial factor that hinders the development of the PPP model is the low yield it brought. The current PPP project yield is around 6\%-8\%. However, for the social business, this rate is not as attractive since the investment from the beginning is huge, along with the fact that the profit it produces needs a long period and the risk is quite high. Currently, in Jiangsu, Anhui, Fujian, Jiangxi, Shandong, Hubei, Guizhou, the project selected by the National Department and Reform Commission for the social business can have a greater difference between profit, with the highest reaching to $8 \%-9 \%$ rate of yield. Meanwhile, the local government doesn't share the more profitable projects to the social business, instead they submit the ones with lower yield and higher risk projects. Therefore, this contributes to that the overall participation is quite low among the social business. Another reason for that is as the ultimate goal for the social business 
and the government is different. There's a risk for the two to push the responsibility when encountering the fact that the risk is not sharing among the two equally, which results in the final failure.

\subsection{The governing of the later phase isn't well structured, and it lacks the sufficient supervision}

The PPP model should incorporate a whole-process participation of the project. It shouldn't just focus on the investment phase from the beginning; what's more important is its later governing phase. However, for the government, when to filter out the suitable social business to cooperate, it put more focus on its financial status, without concerning much on its governing over later phase. Therefore, the social business doesn't have much opportunity to perform its advantage over the technical and professional governing experience, which results a great difficulty in actually reaching an efficient operation. Also, this current PPP model has lack coordinated supervising department, as different leaders in different operation may result in great different criteria for operation; therefore the efficiency of the operation is too low.

\section{The suggestion for further promoting the PPP model in China}

Facing all the problems illustrated above, we need to improve on the aspects of recognition, system perfection, risk sharing, distribution of profit and sufficient supervision in order to promote and achieve a more efficient PPP model.

\subsection{Transform the concept and deepen our recognition}

PPP model is a transition from the project wholly responsible by the government to a project who is cooperated between the social business and the government for the sake of offering services in public welfare. This is not only the innovation in the financing method but also a reform of the financial system and the transformation of government function as well as the reform of the supply side. Therefore, the government needs to change his recognition to understand more optimistic sides the PPP model has brought in, and accordingly elevate the equity consciences and cooperation concept. Also, the traditional investment company usually chooses the project with higher profit. However, in common sense, high profit always associates with higher risks, which may result in the loss of the governing of certain projects. However, as PPP model can bring in equilibrium between the commerce and public welfare, therefore, both parties within should deepen their recognition toward PPP model and apply the contractual spirit.

\subsection{Perfecting the legislation regulation and elevating the protection of system}

The government can use the foreign PPP model's relevant legislation documents as examples to further furnish the legislation for PPP model application in our country. Therefore, based on the aim to make sure every movement can be supported by one clear statement in the legislation, the complete law system can efficiently regulate the participated parties and also protect their profits. Within one complete legislation, we need to specify the responsibilities. For the government, he needs to conduct the promotion at the beginning and the supervision during operation. Then, for the social business, he needs to perform a qualified operation. Meanwhile, when concerning the different responsibilities, we also need to consider that different PPP model may also have differences in its own application based on the marketing environment and the participated parties. Therefore, it needs flexibility under a structural system for the sake of a better operation of PPP projects.

\subsection{Constructing an efficient system for lowering the criteria in joining the PPP model}

A reasonable risk-sharing and profit sharing system is one crucial factor in PPP model. During different stages of the project, it may face countless risks, therefore it is important that the risk can equally be separated into the two parties. Also, during operation and construction, the profit 
yielded should also be equally distributed. This two steps can directly relate to the PPP focus that ' the risk we share, the profit we win together', without maximizing the profit, instead we equalizing it. For this sake, the government, therefore, needs to enforce more financial support, such as provide more guarantee and subsidy for certain middle-size business, encouraging more business joining this PPP with more equalized level for financing requirement with some bigger state-owned business. In order to construct a more variable investment-profit system, we need to construct more methods such as capital securitization to perfect the investment exit system of PPP model and also perfect the middle to long-term investment plan for local government. [6]

\subsection{Deepen the governing and the supervision for the later-phase operation of PPP project}

PPP has solved the financial problem of public service and construction. More importantly, during its later-phase, it needs to focus on the advantage of governing and professional aspect experience the social business has brought in order to compensate the lack of governing offered by the government. As a result, a better efficiency and governing level through a more professional operation method can be achieved. Therefore, when it comes to the analysis of the feasibility of projects, or the beginning design or recognition phase, there should be certain governing over the whole phase of the project being set up to promote the level of technology, governing, overall quality and the service. Meanwhile, the government should also sufficiently perform the supervising role in constructing an inter-departmental supervising agency, along with the introduced social supervision and examination agency to provide more focus over the social efficiency and the profit of the final project.

\section{Summary}

Under this Supply-side reform environment, the promotion of PPP model in China has actually elevated the governing level of projects as well as the quality of public services especially at the aspects of infrastructure construction and public welfare. Also, it provides the social business with more capital, more advanced technology to incorporate with the infrastructure construction, helping to solve financing problems in public services and elevating the efficiency in utilizing the social capital. Also, reaching the ultimate win-win goal, the PPP model helps to compensate the lacks of experience and functions in certain aspects, and ease the financial pressure. This policy in letting the government releasing more rights to the society becomes the one crucial step in achieving the sustainable development under the new normal situation of China. Therefore, we need to continue the promotion and the analysis of PPP model, meanwhile acknowledging the limits of the model during its application in China. Therefore, based on the protection of legislation, the perfection of the system and the continual innovation of the governing, the PPP model can be more developed for the sake of economic needs, with finally achieving the sustainable development under the supply-side reform.

\section{References}

[1]Ji Jiangfan, Cao Yu, Wang Zhifei, Xu Yan.,China's PPP model and its impact on the bond market,Bonds, vol. 05, pp. 69-76,2015.

[2] Wei Jie, Zhang Bao, On the role of Government and risk Prevention under PPP Mode ,Knowledge-based economy,vol.08, pp.7-8,2016

[3]Xu Jing,Study on the Application of PPP Model in Sponge City Construction , Economic Research,vol.36,pp. 104-105,2017.

[4] Cai Ying,A preliminary study of the PPP Model in the context of structural Reform on the supply side ,Administration and Law,vol.41,pp.41-47. 2017. 
[5] Gu Yongchao,Cold thinking on PPP Mode upsurge under the background of supply side Reform, Value engineering,vol.36(04), pp.229-233,2017.

[6]Li Chunxia,Problems and Strategies in the Application of PPP Mode in the context of structural Reform on the supply side, In the financial sector,vol.01,pp.108-110.2018. 